\title{
Design Passive Optical Network Using Multiclass Classification Neural Network
}

\author{
Firman Pratama Dewantara \\ Electrical Engineering \\ Department, \\ Faculty of Engineering, \\ Brawijaya University. \\ Malang, East Java, Indonesia
}

\author{
Sholeh Hadi Pramono \\ Electrical Engineering \\ Department, \\ Faculty of Engineering, \\ Brawijaya University. \\ Malang, East Java, Indonesia
}

\author{
Rahmadwati \\ Electrical Engineering \\ Department, \\ Faculty of Engineering, \\ Brawijaya University. \\ Malang, East Java, Indonesia
}

\begin{abstract}
To require the order of last mile and the increasing demands of high quality of internet, the network architecture of FTTH (Fiber to the Home) has been chosen by numerous ISP (Internet Service Provider). Poor planning does not only increase the infrastructure costs, but it also increases maintenance costs. In this study, the authors focus on the design of passive optical network by using multiclass classification [9] in backpropagation neural network to shorten the FTTH network planning based on passive optical network design to determine final splitter type which refers to the feasibility of QoS (Quality of Service) and Cost Efficiency. Dataset in this study utilizes GIS (Geographic Information System) report with 33 sub-districts in Malang Regency in 2019 data layer. As a result, after 7300 epoch, the accuracy training was $99.99 \%$ and the splitter classification accuracy was $98.76 \%$.
\end{abstract}

\section{Keywords: PON; QGIS; multiclass-classification; quality-of-service}

\section{INTRODUCTION}

Fiber optic (FO) is a current transmission medium that has the reliability of passing data with a large data capacity, has the characteristics of large bandwidth, high transmission speed in gigabit units and has low attenuation. Optical fiber has been widely used in various fields of technology, one of which is in the field of telecommunications networks [1].

With the rapid use of fiber optics in the telecommunications sector, internet penetration in Indonesia increased by $8.9 \%$ in 2019 compared to 2018 . The data was released by the Indonesia Survey Center through APJII (Association of Indonesian Internet Service Providers) [2]. In addition, APJII also continues to improve the availability of access infrastructure by collaborating with network providers through a memberneutral FTTH program [3].

ISP (Internet Service Provider) as an internet network provider as well as a member of APJII has a pivotal role in increasing internet penetration and equity in Indonesia by carrying out the commitment of 5 cities in the first 5 years on the principle license period. This is in accordance with the statement of the chairman of APJII, Jamalul Izza, in discussing the RPM controversy (Draft Ministerial Regulation) regarding to the prohibition on the operation of internet access services outside the scope of its service area. This is also published in PERMENKOMINFO No.7 of 2015 [4]. The commitment of regional services has implications on the broad reach of ISPs in developing internet business.

To meet the increasing demand for last mile (end user) as well as the demands of internet service quality, the FTTH (Fiber to the Home) network architecture has been chosen by many ISPs. However, poor network planning can not only lead to very high infrastructure installation costs, but it can also increase high maintenance costs. This encourages researchers to perform optimizations using various methods. One of the FTTH architectures that is often studied is PON (Passive Optical Network).

PON is an optical fiber-based broadband access network architecture that uses optical passive devices, so it can be used in point-to-multipoint configurations and can increase access speeds from $155 \mathrm{Mbps}$ to $2.4 \mathrm{Gbps}$ and even up to $5 \mathrm{Gbps}$ for GPON. The elements used in PON are passive optical elements such as passive splitters, fiber optic cables and splices so that this technology can simplify the network, simplify protocol synchronization between interconnection devices and reduce costs in terms of network construction [5].

To get quality of service (QOS) optimization, FTTH network planning must notice to several parameters including the total demand in the cluster, bandwidth requirements, OLT placement, splitter placement, and the cable length. The increasing number of ISP operators available in the certain areas can also provide effectiveness in determining the topology and use of the final infrastructure [6]. Apart from the above parameters, device specifications such as the power emitted on the OLT, the power sensitivity of the ONT, the spectral width of the laser are also needed to consider. Feasibility parameters such as rise time, SNR (Signal to Noise Ratio), and BER (Bit Error Rate) are the output of the feasibility parameters.

A related research previously conducted by Mateusz Zotkiewicsz in 2018 entitled "Classifiers Applied to Dimensioning of Splitters in PON Design" compares the PON classification using a neural network and a decision tree. The use of a neural network is better than using a decision tree [7]. Dataset is adapted from Kaltham $\mathrm{Al}$ Romaithi in 2020 entitled "Optimization of Multilayer Design for FTTH Networks Based on Geographical Information" [8]. We utilizes QGIS with OSM (Open 
Street Map) as basic map to provide road and demand data which processed using geoAI/ grass, also using k-means to provide clustered demand and route line. Random OLT point determination is required to process the potential node middle splitter and final splitter and the various report attributes therein. The complete process of collecting dataset in QGIS is explained in section 2. Dataset in this study is generate from 33 sub-districts in Malang Regency in 2019 data layer. The purpose of this research is to shorten design of passive optical network to determine final splitter type which refers to the feasibility of optical transmission QoS (Quality of Service) and Cost Efficiency in FTTH planning.

\section{METHOD}

The concept of the method in this study is shown in Figure 1 below:

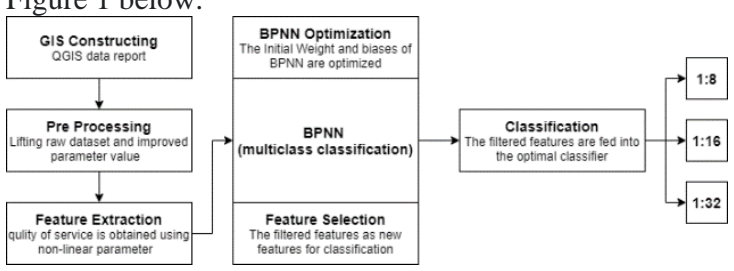

Figure 1. (Research Method)

\subsection{Passive Optical Network}

PON (Passive Optical Network) in this paper are used GPON parameters shown in Table 1 below:

\begin{tabular}{ccc}
\hline ITU-T G.652 & & \\
\hline 652.D (Uplink) & 0.4 & $\mathrm{~dB} / \mathrm{km}$ \\
652.D (Downlink) & 0.3 & $\mathrm{~dB} / \mathrm{km}$ \\
Chormatic Dispersion (Tmat) SMF & 12 & $\mathrm{ps} / \mathrm{nm} . \mathrm{km}$ \\
Intermodal Dispersion (Tmod) MMF & 0 & $\mathrm{ps} / \mathrm{nm} . \mathrm{km}$ \\
\hline Optical Interface & & \\
\hline Sensitifity Receiver & -27 & $\mathrm{dBm}$ \\
Risetime Receiver & 200 & $\mathrm{ps}$ \\
Risetime Transmitter & 150 & $\mathrm{ps}$ \\
\hline Passive Component & & \\
\hline Splitter 1:4 Loss & 7.25 & $\mathrm{~dB}$ \\
Splitter 1:8 Loss & 10.38 & $\mathrm{~dB}$ \\
Splitter 1:16 Loss & 14.1 & $\mathrm{~dB}$ \\
Splitter 1:32 Loss & 17.45 & $\mathrm{~dB}$ \\
Connector Loss & 0.5 & $\mathrm{~dB}$ \\
Redaman Splicing & 0.1 & $\mathrm{~dB}$ \\
\hline
\end{tabular}

Table 1. Passive Optical Specification

The parameters are used to calculate the feasibility of SNR and BER at each potential node, with minimum standard of $\mathrm{SNR}>21.5 \mathrm{~dB}$ and BER> $1 \times 10-9$. The total loss parameter is calculated by using the general link budget in equation 1-12 to ensure the power received is not less than the minimum receiver sensitivity. The risetime budget in this study uses an NRZ type encoding that can carry a large bandwidth.

tsys $=\left(\mathrm{t}_{\mathrm{tx}}{ }^{2}+\mathrm{t}_{\text {chromatic }}{ }^{2}+\mathrm{t}_{\text {modal }}{ }^{2} \mathrm{trx}^{2}\right)^{1 / 2}$

$D_{t}=D(\lambda) . S . L$

$D(\lambda)=\frac{S_{0}}{4}\left(\lambda-\frac{\lambda_{0}^{4}}{\lambda^{3}}\right)$

$t_{s y s}<t_{r}$

$\operatorname{tr}=\frac{0,7}{B r}$
Quality-of-service also involves SNR and Q factor parameters.

$\left(\frac{S}{N}\right)=\frac{\text { Signal Power }}{\text { Shot Noise Power }+ \text { Amplifier Noise Power }}$

Signal Power $=2\left(2 \mathrm{P}_{\mathrm{opt}} \frac{\eta q}{\eta v}\right)^{2} M^{2}$

Noise:

Noise Dark Current $i_{N D}^{2}=2 q i_{D} B$.

Thermal Noise $=\frac{4 k T_{\text {eff }} B}{R_{\text {eq }}}$

Shot Noise $=2 \mathrm{q}\left(2 \mathrm{P} \text { opt } \frac{\eta q}{\eta v}\right)^{2} \mathrm{~B} M^{2} F(M)$

To calculate BER, Q factor needs to be calculated with the following equation:

$(\mathrm{S} / \mathrm{N}) \mathrm{pk} / \mathrm{rms}=20 \log 2 \mathrm{Q}$

$\mathrm{BER}=P e(Q)=\frac{1}{\sqrt{2 \pi}} \cdot \frac{e}{Q}^{-\frac{Q^{2}}{2}}$

\subsection{Dataset}

The data used in this research are the QGIS parameter reports which were processed to produce SNR and BER values. From 33 sub-districts, the data collected is 2727 clusters with various customer capacities for each cluster. From 2727 clusters, 41801 potential node final splitters were produced with a splitter ratio parameter of $1: 8,1: 16$, and 1:32.

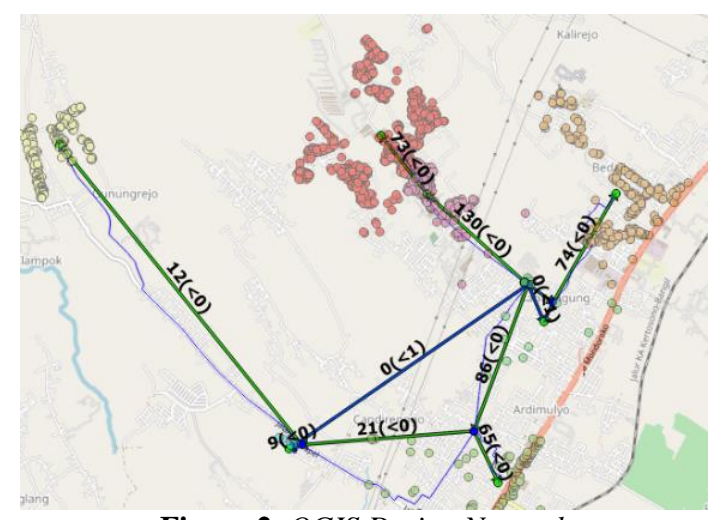

Figure 2. QGIS Design Network

In addition to parameters of power transmission, bitrate and wavelength are required to design the QoS (Quality of Service) ODN (Optical Distribution Network). The transmission power scenario uses $1.5,3,5 \mathrm{~dB}$, bitrate from 10-100 Mbps, wavelengths of 1490 (dual play), and 1550 (triple play). To build a classification model, we use three stages: 1) GIS constructing, 2) Design of QoS (Quality of Service), 3) Determine the passive optical network class label on ODN.

1) Gis Constructing: we make the use of hierarchical features and k-means algorithm provided by the GNI planner of QGIS. Experiments were carried out several times to produce an even distribution of demand in each cluster. After the clusters are generated, we repeated this step to produce several distribution variations in the same district. From the distribution of demand in each cluster, a potential node was generated in the form of a middle splitter and final splitter as well as a rough calculation of loss. Report parameters in GIS was selected to be used as the system training input. 
2) Design Quality of Service: This stage adopts 1-12 equations and aims to produce training data matrices that are in accordance with the feasibility of Quality of Service. The amount of data used has as many as matrices $(1048575,83)$

3) Classification of Training: To determine the training data, we calculate Design Quality of Service first, then select which index or parameter is suitable to be used as training data (eg: BER replaced by $\mathrm{Q}$ factor) because it has a very small value.

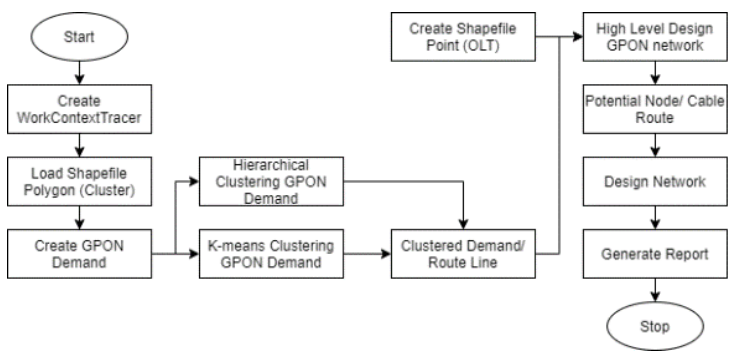

Figure 3. GIS Constructing

\begin{tabular}{|c|c|c|c|c|c|c|c|c|c|c|}
\hline $\mathrm{s}$ & $w$ & bdl & & $1 p$ & $c$ & & rall & sdl & qdl & testing \\
\hline & 0 & & 0.57 & 4.7021815 & & & 0.2620012 & 781.91801 & 13.981398 & \\
\hline 3 & 0 & 1 & 0.69 & 10.791893 & 0 & 69 & 0.3080037 & & $: 7.4625193$ & 1 \\
\hline 5 & 0 & & 0.97 & 9.8789222 & 0 & 97 & 0.2993688 & S188.06218 & 6.8 .8677883 & \\
\hline 6 & 0 & 1 & 0.77 & 4.5565913 & 0 & 77 & 0.2612853 & 590.48283 & 12.149926 & \\
\hline 7 & 0 & 1 & 1.93 & 2.0275388 & 0 & 193 & 0.2522745 & 5 399.617709 & 9.99552125 & \\
\hline 9 & 0 & 1 & 1.45 & 7.5612436 & 0 & 145 & 0.2799795 & 589.59917 & 6.8836613 & 1 \\
\hline 10 & 0 & & 0.73 & 7.8732315 & 0 & 73 & 0.2823593 & 377.5845 & 9.7157919 & 1 \\
\hline 11 & 0 & 1 & 1.64 & 6.2036849 & 0 & 164 & 0.2705465 & 211.33357 & 7,26865882 & 1 \\
\hline 14 & 0 & & 2.17 & 4.212662 & 0 & 217 & 0.2596765 & 5 209.83052 & $=$ & 1 \\
\hline 15 & 0 & 1 & 1.98 & 6.8887327 & 0 & 198 & 0.2751144 & : 145.41756 & 6.0294602 & 1 \\
\hline 19 & 0 & 1 & 2.4 & 2.8284628 & 0 & 240 & 0.2544077 & 2.26.93922 & 8.1077004 & 1 \\
\hline & 0 & & 1.84 & 3.5206422 & 0 & 184 & 0.2567968 & 8298.0678 & 8.6322619 & 1 \\
\hline 21 & 0 & & 1.97 & 2.08392655 & 0 & 197 & 0.2524022 & 354.66584 & 9.41626030 & 1 \\
\hline 24 & 0 & & 1.32 & 0.2227212 & 0 & 132 & 0.2500276 & 58 & : 14.306786 & 1 \\
\hline & & & 1.12 & 1.2998123 & & 112 & 0.2509373 & 7 70.59936 & 13.789474 & 1 \\
\hline 27 & 0 & 1 & 0.02 & 12.601642 & 0 & & 0.3265453 & \begin{tabular}{|l|l}
5723.4139 \\
\end{tabular} & 37.826624 & 1 \\
\hline 29 & 0 & & 0.9 & 8.2265417 & 0 & 90 & 0.2851448 & 266.24904 & 8.1585697 & 1 \\
\hline 30 & 0 & & 0.64 & 6.97269966 & & 64 & 0.2757016 & 5487.3306 & 11.037783 & \\
\hline 31 & 0 & & 1.91 & & 0 & 191 & 0.2661905 & S 200.28195 & \begin{tabular}{|l}
7.0760504 \\
\end{tabular} & 1 \\
\hline 32 & & & & 7.6674408 & & & & & 7.6644357 & \\
\hline
\end{tabular}

$s f$ train.drop(sf_train[sf_train. $k<1]$. index, inplace $=$ True $)$ (123001, 11)

Table 2. Dataset using dataframe.drop

\subsection{Network Architecture}

We used 3 layers of MLP (Multi-Layer Perceptron) in this study. In Figure 2, the input layer has eight nodes in the form of wavelength, bitrate, length, capacity, tx, risetime, $\mathrm{SNR}$, and BER. Those eight layers in the hidden layer are for adding non-linear parameters into the model resulting in three output layer nodes as the final splitter multiclass classification [9] based on the quality-of-service feasibility value.

We did an experiment using several hidden layer models and a different number of neurons and got a fit model using a hidden layer 8,8 . The architecture above was chosen because it produces minimal loss and results in a fairly effective training process compared to the combination of hidden layers and other neurons.

Algorithm for the proposed system:

\section{Initiation of weights using small random numbers}

\section{Feed Forward}

- Each input unit $\left(\mathrm{x}_{\mathrm{i}}, \mathrm{i}=1, \ldots \ldots, \mathrm{n}\right)$ was passed to the hidden layer

- Each hidden layer $\left(\mathrm{z}_{\mathrm{j}}, \mathrm{z}=1, \ldots . ., \mathrm{p}\right)$ added the weight of the input signal $Z_{-} \mathrm{in}_{\mathrm{jk}}=\mathrm{V}_{0 \mathrm{j}}+\sum_{i=1}^{n} x_{i} v_{i j}$, by applying the activation function $\mathrm{Z}_{\mathrm{j}}=f\left(\mathrm{Z}_{-} \mathrm{in}_{\mathrm{j}}\right)$
- For example, the activation function used is sigmoid y $=f(\mathrm{x})=\frac{1}{1+e^{-x}}$, then this signal was sent to all output units.

- Each output unit (yk, $\mathrm{k}=1, \ldots . . \mathrm{m}$ ), added up the input and weight $\mathrm{Y} \_\mathrm{in} \mathrm{k}_{\mathrm{k}}=\mathrm{w}_{0 \mathrm{j}}+\sum_{k=1}^{p} z_{j} v_{j k}$ by applying the activation function $Y j=f\left(Y \_\right.$ink $)$

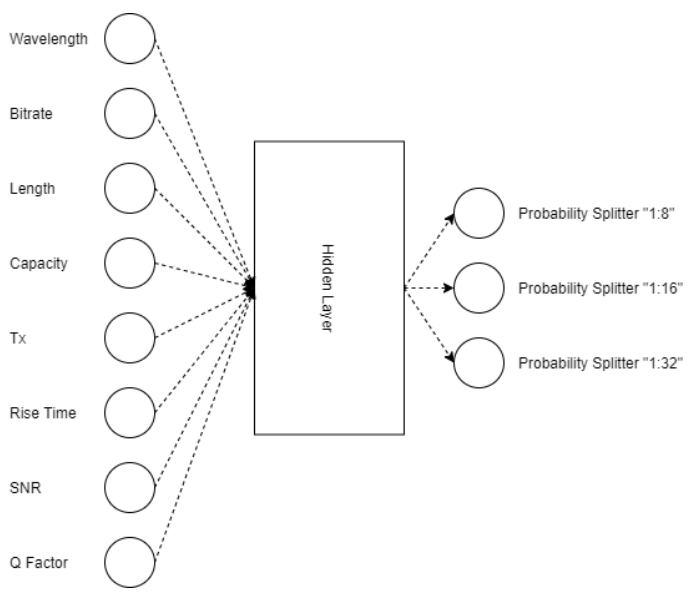

Figure 4. Neural Network Architecture

\section{Backpropagation}

Each output unit $\left(\mathrm{y}_{\mathrm{k}}, \mathrm{k}=1, \ldots \ldots, \mathrm{m}\right)$ received the training input by calculating the error $\delta_{\mathrm{k}}=\left(\mathrm{t}_{\mathrm{k}}-\mathrm{y}_{\mathrm{k}}\right) \mathrm{f}^{\prime}\left(\mathrm{y}_{-} \mathrm{in}_{\mathrm{k}}\right)$

- Calculating the correction for weight and bias $\Delta \mathrm{w}_{\mathrm{jk}}=$ $\alpha \delta_{\mathrm{k}} \mathrm{x}_{\mathrm{j}}, \Delta \mathrm{w}_{0 \mathrm{k}}=\alpha \delta_{\mathrm{k}}$

- Each hidden layer $(\mathrm{z}, \mathrm{z}=1, \ldots . \mathrm{p})$ added up the input delta $\delta \_$in $_{j}=\sum_{k=1}^{m} \delta_{k} w_{j k}$ and calculated the error $\delta_{\mathrm{j}}=$ $\delta \_\mathrm{in}_{\mathrm{j}} f \overline{\left(\mathrm{x} \_\mathrm{in}\right.}$ )

- Calculating weight and bias correction $\Delta \mathrm{v}_{\mathrm{ij}}=\alpha \delta_{\mathrm{j}} \mathrm{x}_{\mathrm{i}}$

\section{Fixing the weight and bias}

- $\quad$ Each output unit $\left(\mathrm{y}_{\mathrm{k}}, \mathrm{k}=1, \ldots \ldots, \mathrm{m}\right)$ updated the weight and bias $(\mathrm{j}=0,1, \ldots \ldots, \mathrm{p})$

- $\quad \mathrm{w}_{\mathrm{jk}}($ new $)=\mathrm{w}_{\mathrm{jk}}($ old $)+\Delta \mathrm{w}_{\mathrm{jk}}$

- Each hidden layer unit $\left(\mathrm{z}_{\mathrm{j}}, \mathrm{z}=1, \ldots \ldots, \mathrm{p}\right)$ updated the weight and bias $(\mathrm{i}=0,1, \ldots . ., \mathrm{n})$

- $\quad \mathrm{v}_{\mathrm{ij}}($ new $)=\mathrm{v}_{\mathrm{ij}}(\mathrm{old})+\Delta \mathrm{v}_{\mathrm{ij}}$

\section{Training stopped}

\subsection{Implementation}

We conducted an experiment using several hidden layers and hyperparameter model. The input feature will be streamed to all hidden layer neurons where each feature will be multiplied by weight and added bias at the same time, as well as the output from the hidden layer to the output layer. After the feature reach the output layer, the classification loss will be calculated using Categorical Cross-Entropy (CCE) loss. The target for multi-class classification is a one-hot vector, meaning has one on a single position and 0's everywhere else [10] [11].

Loss CCE $=-\sum_{x} \mathrm{p}(x) \cdot \log \mathrm{q}(x)$

$\mathrm{p}(\mathrm{x})=$ Probability of class $\mathrm{x}$ in the "target" matrix 
$\mathrm{q}(\mathrm{x})=$ Probability of class $\mathrm{x}$ in the "predict" matrix

The training process uses Early Stopping parameters with Patient (Number of epochs with no improvement after which training will be stopped) [12] after the 1000th epoch and Model Checkpoint monitoring Val accuracy mode 'max' to avoid overfitting during training. Training stopped at the 7300th epoch of the 20,000 epochs specified. MLP used 5 neurons in the hidden layer with the sigmoid activation function and three neurons in the output layer with the SoftMax activation function [10] [11]. The author also conducted an experiment using hyperparameter [citation]. This experiment aims to find a neural network model that produces the best accuracy.

es $=$ EarlyStopping $($ monitor $=$ 'val_loss', mode $=$ 'min', verbose $=1$, patience $=1000$ )

$m c=$ ModelCheckpoint ('best_model.h5', monitor = 'val_accuracy', mode = 'max', verbose $=1$, save_best_only $=$ True)

\section{RESULT AND DISCUSSION}

\subsection{Training Result}

After 7300 epochs, we evaluate the model using the test data. The training accuracy is around $99.99 \%$ and the testing accuracy is around $98.76 \%$.

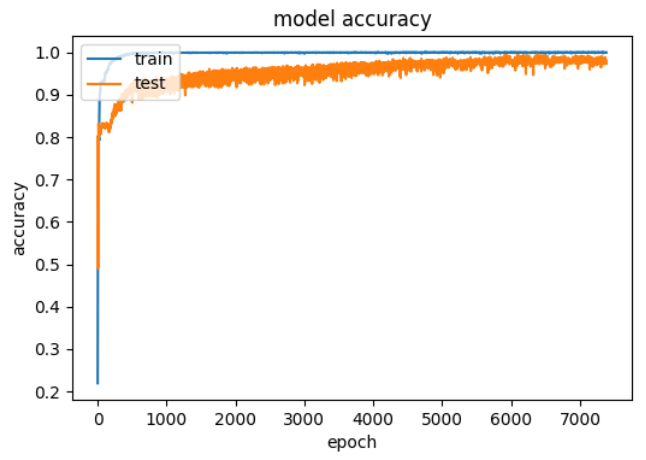

Figure 5. Training and Testing Accuracy Result

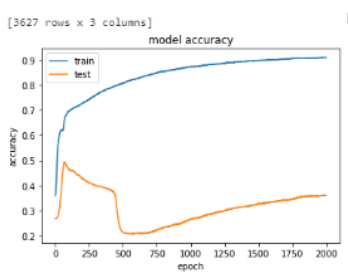

(a)

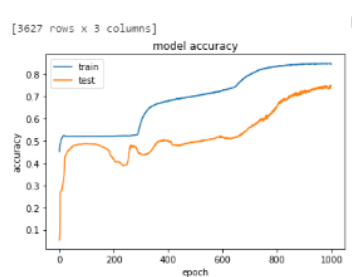

(c)

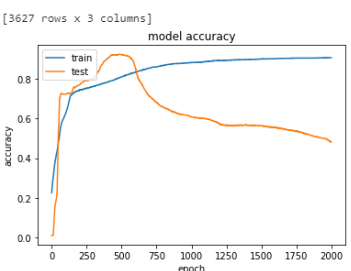

(b)

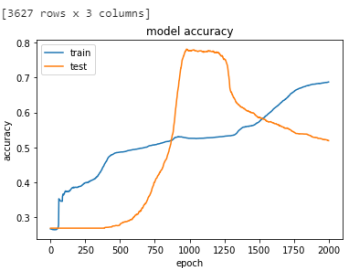

(d)
Figure 6. Overfit (a) relu 8 batch-size 64, adam 0.00001 (b) relu 7 batch-size 64, adam 0.00001 (c) 4 relu, 8 sigmoid, batch-size 16 , sgd 0.0001 (d) 7 relu, 5 sigmoid, $32,0.000001$

Epoch 07299: val_accuracy did not improve from 0.99559

\section{Epoch 7300/20000}

116/116 [===============================] - 0s 1ms/step - loss: 5.2663e-04 - accuracy: 0.9997 - val_loss: 0.1006 - val_accuracy: 0.9876

\subsection{One-hot Encoding}

The target for multi-class classification is a one-hot vector, meaning has 1 on a single position and 0 's everywhere else [13].

\begin{tabular}{|c|c|c|}
\hline Layer (type) & Output Shape & Param \# \\
\hline input_23 (InputLayer) & {$[($ None, 8$)]$} & $\theta$ \\
\hline dense_44 (Dense) & (None, 5) & 45 \\
\hline dense_45 (Dense) & (None, 3) & 18 \\
\hline
\end{tabular}

Figure 7. Neural Network Model

$\begin{array}{rrrr} & 1: 8 & 1: 16 & 1: 32 \\ 8226.0 & 1.000000 & 1.181006 \mathrm{e}-08 & 2.144990 \mathrm{e}-29 \\ 3990.0 & 1.000000 & 1.302063 \mathrm{e}-08 & 2.111058 \mathrm{e}-29 \\ 4013.0 & 1.000000 & 1.302063 \mathrm{e}-08 & 2.111058 \mathrm{e}-29 \\ 5186.0 & 1.000000 & 2.197091 \mathrm{e}-08 & 4.575406 \mathrm{e}-29 \\ 5209.0 & 1.000000 & 2.197091 \mathrm{e}-08 & 4.575406 \mathrm{e}-29 \\ 2016.0 & 1.000000 & 8.022938 \mathrm{e}-10 & 3.542995 \mathrm{e}-31 \\ 2030.0 & 1.000000 & 8.022938 \mathrm{e}-10 & 3.542995 \mathrm{e}-31 \\ 2884.0 & 1.000000 & 1.227288 \mathrm{e}-09 & 6.593431 \mathrm{e}-31 \\ 2898.0 & 1.000000 & 1.227288 \mathrm{e}-09 & 6.593431 \mathrm{e}-31\end{array}$

Figure 8. Multiclass Classification Result (One-hot Encoding)

Some classifications resulted in inaccurate predictions of final splitter ratios. However, the classification results produced the optimum final splitter in FTTH network planning by prioritizing the cost efficiency factor without eliminating the QoS factor.

$\begin{array}{llll}3893.0 & 0.013101 & 9.868993 e-01 & 1.065835 e-16 \\ 5089.0 & 0.003422 & 9.965783 e-01 & 2.124624 e-16\end{array}$

Figure 9. Cost Efficiency Result

\subsection{Loss CCE}

On the section 2.4, it has been explained that the implementation of training used CategoricalCrossEntropy. loss CCE is calculated using equation 13 [13]:

Sample (id 3893)

0

0.003422 Loss 1:8?

Target $=1$, Prediction $=0.9868998$ Loss $1: 16$ ?

0

$2.12-16$ Loss $1: 32$ ?

Loss $1: 8=-\mathrm{p}(1: 8) \cdot \log \mathrm{q}(1: 8)$

$=-0 . \log (0.003422)$

$=0$

Loss $1: 16=-p(1: 16) \cdot \log q(1: 6)$

$=-1 . \log (0.9868998)$

$=0,0057269$

$\operatorname{Los} 1: 32=-p(1: 32) \cdot \log q(1: 32)$

$=-0 . \log \mathrm{q}(2.12 \mathrm{E}-16)$

$=0$

\subsection{QoS (Quality of Service)}

The data testing id 3893 will be tested using the equation in section 2.1. The parameter of testing data are as follows:

Parameter:

s $\quad=1(1: 8)$ 


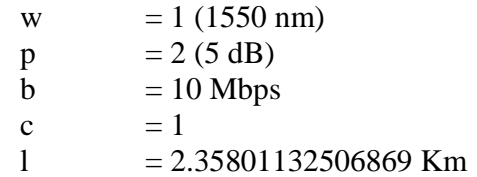

Final splitter planning using 1: 8 resulted in a QoS calculation that was in excellent status where the risetime budget was 0.2530716, SNR 55.757096, and BER 0. Multiclass Classification predicted that the final splitter ratio was possible to use a larger ratio, namely $1: 16$ which resulted in risetime as 0.253072 , SNR 48.43843, and BER 0 . This showed that the feasibility of QoS can still be reduced to the minimum standard limits of SNR and BER to produce cost efficiency in network planning. This simplifies the QoS input parameters without calculating manually to produce optimal FTTH network planning (QoS and cost efficiency). The following is a comparison table of $1: 8$ and 1:16:

\begin{tabular}{|c|c|c|c|c|}
\hline & $\mathrm{rt}$ & $\mathrm{SNR}(\mathrm{dB})$ & BER & QoS \\
\hline $1: 8$ & 0.2530716 & 55.757096 & 306.77841 & 0 yes \\
\hline 1:16 & 0.2530716 & 48.438427 & 132.09651 & 0 yes \\
\hline
\end{tabular}

Table 3. Quality of Service id 3893

The authors tried to prove that by adjusting the QoS parameter to the standard value of feasibility, it can result in cost efficiency optimization. In this experiment, we used data testing id 3893 by changing the parameter of the capacity to be 100 homepassed, SNR using a minimum standard of 21.5 and BER 1E10-9. Following are the prediction results:

1s 2ms/step - loss: 0.0014 - accuracy: 0.9998 - val_loss: 0.0480 - val_accuracy: 0.9876

\section{[[2.0661601e-26 2.6315628e-03 9.9736845e-01]]}

Referring to the clarification system result, the authors calculated manually using final splitter ration 1:32. The results are as follows:

\begin{tabular}{|c|c|c|c|c|}
\hline & $\mathrm{rt}$ & SNR(dB) & $\mathrm{Q}$ & BER \\
\hline $1: 32$ & 0.2530716 & 35.7571 & 30.6778 & $5.629 \mathrm{E}-207$ yes \\
\hline
\end{tabular}

Table 4. Quality of Service id 3893 1:32

\section{CONCLUTION}

\subsection{Conclusion}

From the results of the research, several conclusions can be drawn:

1. The design of passive optical network (final splitter) can be done using the Multiclass Classification method with a multilayer perceptron Neural Network.

2. The val accuracy of $98.76 \%$ can produce QoS (Quality of Service) feasibility in the design of passive optical network FTTH network.

3. The final splitter determination using Multiclass Classification can increase the cost efficiency of FTTH network development because the increased capacity of the splitter ratio can reduce the need for distribution cables.

\subsection{Suggestions}

Design Passive Optical Network using Multiclass Classification can utilize the ISP dataset such as ONMS (Optical Network Monitoring System) and CRM (Customer Relationship Management) to be applied in network expanding.

\section{References}

[1] N. Massa, "Fiber Optic Telecommunication," dalam Fundamentals of Photonics, Springfield, University of Connecticut, 2000, p. 293.

[2] Indonesia Survey Center, "Laporan Survei Internet APJII 2019-2020 (Q2)," APJII (Asosiasi Penyelenggara Jasa Internet Indonesia), Jakarta, 2020.

[3] A. (. P. J. I. Indonesia), "Buletin APJII," Edisi 55, p. 1, Januari 2020.

[4] Kementrian Komunikasi dan Informatika Republik Indonesia, "kominfo.go.id," Kementrian Komunikasi dan Informatika Republik Indonesia, 20 Desember 2017. [Online]. Available: https://www.kominfo.go.id/content/detail/12084/bi snis-penyelenggara-jasa-internet-akan-dibatasipengusaha-keberatan/0/sorotan_media. [Diakses 1 Maret 2021].

[5] T. Thangappan, "Review of Dynamic Bandwidth Allocation in GPON," IEEE, 2020.

[6] A. Guidotti dan R. Capannini, "Optimized Design of Multi-Operator FTTH PONs," Conference: 20th Italian National Conference on Photonic Technologies, p. 1, 2018.

[7] M. Zotkiewicz, "Classifiers Applied to Dimensioning of Splitters in PON Design," IEEE, vol. 10, pp. 1-10, 2018.

[8] K. A. Romaithi, A. Ouali, K. Poon, Y. P. Kong dan S. B. Lee, "Optimization of Multilayer Design for FTTH Networks Based on Geographical Information," IEEE, 2020.

[9] B. Erkal, S. Basak dan A. Ciloglu, "Multiclass Classification of Brain Cancer with Machine Leraning Algorithm," IEEE, 2020.

[10] M. Rohmatillah, S. H. Pramono dan Rahmadwati, "Automatic Cervical Cell Classification Using Features Extracted by Convolutional Neural Network," IEEE, 2018.

[11] M. Rohmatillah, S. H. Pramono dan R. Asyari, "Implementation of Deep Learning Based Method for Optimizing Spatial Diversity MIMO Communication," Indonesian Journal of Electrical Engineering and Informatics (IJEEI), 2020.

[12] G. Vrbancic dan A. V. Podgorelec, "Transfer Learning With Adaptive Fine-Tuning," IEEE, 2020.

[13] towardsdatascience, "Toward Data Science," Toward Data Science, [Online]. Available: https://towardsdatascience.com/cross-entropy-forclassification-d98e7f974451. [Diakses 28 April 2021]. 